\title{
Metabolic Syndrome and Role of Mitochondrial Calcium Handling
}

\author{
Julieta Díaz-Juárez ${ }^{1}$ and Jorge Suarez ${ }^{2^{*}}$ \\ ${ }^{1}$ Universidad Autónoma Metropolitana Xochimilco, México Clty, México \\ ${ }^{2}$ Department of Medicine, University of California, San Diego, USA
}

*Corresponding author: Jorge Suarez, MD, PhD, Research Scientist, Department of Medicine, 5063 Biomedical Sciences Building, University of California, San Diego, La Jolla, California, 92093-0618, USA, Tel: 858-534-9931; Fax: 858-534-9932; E-mail: jsuarez@ucsd.edu

Received date: Nov 02, 2016; Accepted date: Nov 03, 2016; Published date: Nov 10, 2016

Copyright: (c) 2016 Díaz-Juárez J, et al. This is an open-access article distributed under the terms of the Creative Commons Attribution License, which permits unrestricted use, distribution, and reproduction in any medium, provided the original author and source are credited.

\section{Editorial}

Metabolic syndrome (MetS) is a growing public health problem worldwide. MetS prevalence in the United States has been investigated recently. The article in this journal by Miller and Fridline (1) reported a prevalence of MetS in the total studied cohort of $34.7 \pm 1.4 \%$. The risk factor with the highest proportion and risk for the total sample and by sex was waist circumference (WC). Women had a higher prevalence of WC, HDL, and blood pressure risk factors compared to men who had a higher prevalence of triglycerides and fasting plasma glucose [1]. Furthermore, MetS is an arrangement of cardiovascular and metabolic risk factors that dramatically increase cardiovascular mortality and morbidity and type 2 diabetes [2-4]. These alarming data emphasize the importance of MetS as an epidemic and dangerous disease. The magnitude of the prevalence of MetS also signals to the complexity of the problem.

MetS is characterized by central obesity, dyslipidemia, compromised fasting glucose, and hypertension [5]. However, the pathophysiologic mechanisms that lead to MetS are incompletely understood. It is well accepted that genetic and environmental factors determine the development of MetS. Therapeutic approaches to modify life style to correct MetS are established. Nevertheless, the prevalence of MetS increases worldwide. Therefore, there is an extraordinary need for innovative therapeutic approaches.

Mitochondria play central roles in energy metabolism, cell signaling and apoptosis regulation. It has been proposed that dysfunctional mitochondria may contribute to the development of metabolic disorders [6].

Mitochondrial abnormalities associated with MetS target genetic factors, mitochondrial morphology, oxidative phosphorylation, $\mathrm{Ca}^{2+}$ handling and ROS, mitochondrial dysfunction and insulin signaling [7]. Therefore, mitochondria are a natural target for metabolic disorders [7]. The question is: can we repair the dysfunctional mitochondria? Possibly yes.

Mitochondrial free $\mathrm{Ca}^{2+}$ concentration $\left(\left[\mathrm{Ca}^{2+}\right] \mathrm{m}\right)$ is a mayor modulator of mitochondrial metabolism and energy production. $\left[\mathrm{Ca}^{2+}\right] \mathrm{m}$ is governed by a complex set of mechanisms influencing mitochondrial matrix $\mathrm{Ca}^{2+}$ uptake and release which have been reviewed $[8,9]$. Briefly, the outer mitochondrial membrane (OMM) is quite $\mathrm{Ca}^{2+}$ permeable [10], but import across the inner mitochondrial membrane (IMM) is highly regulated. An important contributor to mitochondrial $\mathrm{Ca}^{2+}$ uptake is the mitochondrial $\mathrm{Ca}^{2+}$ uniporter complex (MCUC) with the mitochondrial $\mathrm{Ca}^{2+}$ uniporter (MCU) serving as a highly selective channel that moves $\mathrm{Ca}^{2+}$ ions across the IMM dependent on mitochondrial membrane potential $(\Delta \psi \mathrm{m})$. Although this information has been known for decades, only recently, integrative genomics methods enabled the discovery of the molecular nature of the uniporter pore of MCUC, and its regulatory subunits, MCUb, MICU1 and MICU2, and EMRE [11-16]. However, the physiological role of the MCUC remains controversial [17]. A new report demonstrated that simulated hyperglycemia in cardiac myocytes reduces $\left[\mathrm{Ca}^{2+}\right] \mathrm{m}$, and glucose oxidation with an increase in fatty acid oxidation [18]. Furthermore. Diaz-Juarez et al. demonstrated in the same report that restoring $\left[\mathrm{Ca}^{2+}\right] \mathrm{m}$ concentration to normal levels by genetically expressing MCU normalized glucose and fatty acid metabolism in spite of simulated hyperglycemia. These findings point out a possible pathophysiological role of MCUC in simulated hyperglycemia. However, abnormalities in mitochondrial $\mathrm{Ca}^{2+}$ handling in obesity, MetS or diabetes are incompletely investigated. While metabolic abnormalities in MetS are well established the pathophysiologic mechanisms involved remain unknown. We do not know whether mitochondrial $\mathrm{Ca}^{2+}$ handling plays a role and whether correcting mitochondrial $\mathrm{Ca}^{2+}$ handling will improve these metabolic disorders.

Certainly the prevalence of MetS is alarming, however, new therapeutic approaches that are arising bring hope to people fighting this disease.

\section{Funding}

This Manuscript was supported by Grant from UCMEXUSCONACYT (CN 15-1489).

\section{References}

1. Miller B, Fridline M (2016) Metabolic Syndrome Prevalence and Risk in the United States based on NHANES 2001-2012 Data. J Metabolic Synd 5: 203.

2. Dekker JM, Girman C, Rhodes T, Nijpels G, Stehouwer CD, et al. (2005) Metabolic Syndrome and 10-Year Cardiovascular Disease Risk in the Hoorn Study. Circulation 112: 666-673.

3. Galassi A, Reynolds K, He J (2006) Metabolic syndrome and risk of cardiovascular disease: a meta-analysis. Am J Med 119: 812-819.

4. Isomaa B, Almgren P, Tuomi T, Forsén B, Lahti K, et al. (2001) Cardiovascular morbidity and mortality associated with the metabolic syndrome. Diabetes Care 24: 683-689.

5. Tziomalos K, Athyros VG, Karagiannis A, Mikhailidis DP (2010) Endothelial dysfunction in metabolic syndrome: Prevalence, pathogenesis and management. Nutrition, Metabolism and Cardiovascular Diseases 20: 140-146.

6. Peinado JR, Diaz-Ruiz A, Frühbeck G, Malagon MM (2014) Mitochondria in metabolic disease: getting clues from proteomic studies. Proteomics 14: 452-466.

7. Sorriento D, Pascale AV, Finelli R, Carillo AL, Annunziata R, et al. (2014) Targeting mitochondria as therapeutic strategy for metabolic disorders. Scientific World Journal 2014: 1-9. 
Citation: Díaz-Juárez J, Suarez J (2016) Metabolic Syndrome and Role of Mitochondrial Calcium Handling. J Metabolic Synd 5: e119. doi:

Page 2 of 2

8. Gunter TE and Pfeiffer DR (1990) Mechanisms by which mitochondria transport calcium. Am J Physiol 258: C755-C786.

9. Rizzuto R, Pinton P, Carrington W, Fay FS, Fogarty KE, et al. (1998) Close contacts with the endoplasmic reticulum as determinants of mitochondrial Ca2+ responses. Science 280: 1763-1766.

10. Santo-Domingo J, Demaurex N (2010) Calcium uptake mechanisms of mitochondria. Biochim Biophys Acta 1797: 907-912.

11. Baughman JM, Perocchi F, Girgis HS, Plovanich M, Belcher-Timme CA, et al. (2011) Integrative genomics identifies MCU as an essential component of the mitochondrial calcium uniporter. Nature 476: 341-345.

12. De Stefani D, Raffaello A, Teardo E, Szabň I, Rizzuto R (2011) A fortykilodalton protein of the inner membrane is the mitochondrial calcium uniporter. Nature 476: 336-340.

13. Perocchi F, Gohil VM, Girgis HS, Bao XR, McCombs JE, et al. (2010) MICU1 encodes a mitochondrial $\mathrm{EF}$ hand protein required for $\mathrm{Ca}(2+)$ uptake. Nature 467: 291-296.
14. Plovanich M, Bogorad RL, Sancak Y, Kamer KJ, Strittmatter L, et al. (2013) MICU2, a paralog of MICU1, resides within the mitochondrial uniporter complex to regulate calcium handling. PLoS One 8: e55785.

15. Raffaello A, De Stefani D, Sabbadin D, Teardo E, Merli G, et al. (2013) The mitochondrial calcium uniporter is a multimer that can include a dominant-negative pore-forming subunit. EMBO J 32: 2362-2376.

16. Sancak Y, Markhard AL, Kitami T, Kovács-Bogdán E, Kamer KJ, et al. (2013) EMRE is an essential component of the mitochondrial calcium uniporter complex. Science 342: 1379-1382.

17. Pendin D, Greotti E, Pozzan (2014) The elusive importance of being a mitochondrial $\mathrm{Ca}(2+)$ uniporter. Cell Calcium 55: 139-145.

18. Diaz-Juarez J, Suarez J, Cividini F, Scott BT, Diemer T, et al. (2016) Expression of the Mitochondrial Calcium Uniporter in Cardiac Myocytes Improves Impaired Mitochondrial Calcium Handling and Metabolism in Simulated Hyperglycemia. Am J Physiol Cell Physiol. 